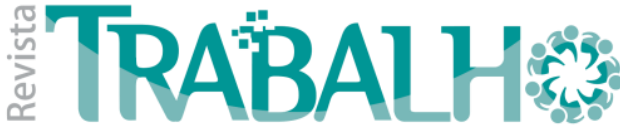 \\ (En)Cena
}

\section{MARXISMO E PSICODINÂMICA DO TRABALHO: APROXIMAÇÕES POSSÍVEIS}

\author{
Marxism and psychodynamics of work: possible approximations \\ Marxisme et psychodynamique du travail: approximations possibles \\ Marxismo y psicodinámica del trabajo: aproximaciones posibles
}

Luciano Alvarenga Montal vão ${ }^{1}$

Doutorando em Psicologia na Universidade Federal do Rio Grande do Norte (UFRN) na linha Clínicas do trabalho e processos organizacionais. Membro do Grupo de Estudos e Pesquis as Sobre o Trabalho (GEPET UFRN) e do GT Processos Psicoss ociais, Organizações e Trabalho (GPPOT). Servidor técnico adminis trativo em educação licenciado (Instituto Federal de Goiás), professor no magistério superior e membro da diretoria ampliada do Sindicato dos Profes sores do Estado de Goiás (SINPRO-GO).

\begin{abstract}
Resumo
O presente artigo tem como objetivo promover a aproximação entre o marxismo e a clínica psicodinâmica do trabalho a partir da reconstituição da categoria trabalho em ambos os modelos teóricos. No itinerário que levou Dejours da psicopatologia do trabalho à teoria do trabalho vivo - transitando por diversas bases teóricas e epistemológicas - a perspectiva recente do trabalho enquanto mediador da emancipação conduzirá o autor a uma aproximação crítica com Marx a qual, no nosso entendimento, abre um novo horizonte político para as nossas práticas clínicas orientadas pela psicodinâmica do trabalho. Em um contexto laboral marcado pelo triunfo da ideologia orgânica do capital e pelo esvaziamento do político, é tarefa necessária resgatar as potencialidad es do trabalho para o estabelecimento de laços sociais de solidariedade e cooperação e colocar na ordem do dia a construção de uma nova política do trabalho.
\end{abstract}

Palavras-Chave: Psicodinâmica Do Trabalho; Marxismo; Emancipação; Política Do Trabalho.

\begin{abstract}
This article aims to promote the approximation between marxism and the psychodynamic and clinic of work through the reconstitution of the work category in both theoretical models. In the Dejours' itinerary from psychopathology of work to living work theory - through various theoretical and epistemological bases - the recent perspective of work as an emancipation mediator will lead the author to a critical approximation with Marx highlighting a new political horizon for clinical practices oriented by the p sychodynamics of work. In a labor context marked by the triumph of the organic ideology of capital and political emptiness, it is a task to redeem the potential of work to establish social bonds of solidarity and cooperation and to place on the agenda the construction of a new labor policy.
\end{abstract}

Keywords: Psychodynamic Of Work; Marxism; Emancipation; Labor Policy.

\section{Résumé}

Cet article vise à promouvoir l'approximation entre le marxisme et la clinique psychodynamique du travail à partir de la reconstitution de la catégorie travail dans les deux modèles théoriques. Dans litinéraire qui conduit Dejours de la psychopathologie du travail à la théorie du travail vivant - en passant par diverses bases théoriques

$1 \underline{\text { lucianoalvarengam@gmail.com }}$ 
et épistémologiques - la perspective récente du travail comme médiateur de l'émancipation conduira l'auteur à une approximation critique avec Marx qui, à notre sens, ouvre une nouvel horizon politique pour nos pratiques cliniques orientées par la psychodynamique du travail. Dans un contexte de travail marqué par le triomphe de l'idéologie organique du capital et la vidange de l'homme politique, il faut redéfinir le potentiel du travail pour l'établissement de liens sociaux de solidarité et de coopération et de mettre à l'agenda une nouvelle politique du travail.

Mots-clés: Psychodynamique Du Travail; Marxisme; Emancipation; Politique Du Travail.

\section{Resumen}

Este artículo tiene como objetivo promover la aproximación entre el marxismo y la clínica psicodinámica del trabajo a través de la reconstitución de la categoría de trabajo en ambos modelos teóricos. En el itinerario que llevó Dejours desde la psicopatología del trabajo hasta la teoría del trabajo viviente - a través de diversas bases teóricas y epistemológicas - la perspectiva reciente del trabajo como mediador de emancipación conducirá al autor a un enfoque crítico con Marx creando un nuevo horizonte político para prácticas clínicas orientadas por la clínica psicodinámica del trabajo . En un contexto laboral marcado por el triunfo de la ideología orgánica del capital y el vacío político, es una tarea rescatar el potencial del trabajo para establecer vínculos sociales de solidaridad y cooperación y para poner en la agenda la construcción de una nueva política laboral.

Palabras claves: Psicodinámica Del Trabajo, Marxismo; Emancipación; Política Laboral.

\section{Introdução}

Na mitologia grega, Sísifo é um sujeito astuto e renitente que, ao enfrentar a ira dos deuses e descumprir ordens superiores, recebe a seguinte penalidade: rolar um rochedo incessantemente até $\mathrm{o}$ cimo de uma montanha de onde, ao final de sua jornada diária, a pedra rolava montanha abaixo sugada pela força de seu próprio peso. No resgate filosófico da mitologia empreendido por Albert Camus em "O Mito de Sísifo - ensaio sobre o absurdo", o personagem corresponde à metáfora de um trabalhador braçal que tem no seu labor cotidiano uma atividade "inútil e sem esperança". Como afirma o autor, o operário "trabalha todos os dias de sua vida na mesma tarefa e esse destino não é menos absurdo" (Camus, 2010 pp. 78-79).

O mundo e a realidade do trabalho certamente se modificaram muito desde a publicação do texto de Camus, em 1941. Não mais "Sísifos", nem tampouco o operário taylor-fordista de Tempos Modernos: o trabalho na sociedade contemporânea é uma complexidade impossível de se retratar numa caricatura, seja ela filosófica ou cinematográfica. E o trabalhador, por sua vez, não é redutível a uma massa amorfa e homogênea, de maneira também que é impossível apreendê-lo sem lançar mão de outros vieses que transcendem a questão de sua prática laborativa, do seu trabalho.

No entanto, à revelia dos avanços tecnológicos e das novas teorias de gestão organizacional que apregoam a proatividade, a criatividade e a autonomia, nos parece ainda coerente questionar: será que o trabalhador contemporâneo já se viu livre do "suplício indescritível em que todo o ser se ocupa em não completar nada" (Camus, 2010, p. 78). Será que a nossa atividade laborativa no tempo presente adquiriu sentido e legitimidade, ou continua desprovida de nexo, como o destino-penitência de Sísifo? São questionamentos que emergem quando nos debruçamos sobre a realidade do mundo do trabalho no capitalismo contemporâneo, e que se mostram ainda mais pertinentes se nos atentarmos para o crescente número de trabalhadores adoecidos em razão do seu próprio trabalho.

Para Karl Marx, o trabalho é atividade ontológica humana, responsável pelo processo de humanização do sujeito e por torná-lo diferente, em essência, dos demais animais. Ao intervir conscientemente na Natureza e transformá- 
la conforme as suas necessidades, o sujeito modifica a matéria natural ao mesmo tempo em que modifica a si próprio, à sua própria natureza. Portanto, podemos afirmar que existe uma relação intrínseca entre a existência humana e o trabalho. $\mathrm{O}$ trabalho, e todo desenvolvimento material dele decorrente, só existem face à ação humana sobre a Natureza. E, por conseguinte, o homem só existe em razão de sua atividade produtiva, de seu trabalho. Dito de outra forma: a transformação da Natureza por intermédio da atividade produtiva intencional do homem é a condição sine qua non da produção e reprodução de sua própria existência (Marx, 1867/2013).

Se, para Marx, o trabalho é o substrato da humanização e condição da própria existência humana, para Cristophe Dejours - fundador e maior expoente da clínica psicodinâmica do trabalho $-\mathrm{o}$ trabalho é o alicerce da nossa subjetividade. Para além de um movimento de transformação da Natureza ou integração a uma classe social, o trabalho representa $\mathrm{o}$ estabelecimento de vínculos psicoafetivos, o enfrentamento de conflitos inter e intrasubjetivos, e a formação de uma identidade nos marcos da vivência laboral. Ao trabalho ordinário de produção, integra-se $o$ trabalho do psiquismo, de modo que a atividade produtiva para a psicodinâmica é uma provação constante para a subjetividade. Além do seu papel central na vida subjetiva dos indivíduos, o trabalho é também, segundo Dejours, estruturante das relações sociais e políticas de modo que o cotidiano laboral tem ampla ressonância no âmbito geral da sociedade (Dejours, 1980/1995, 2004, 2008, 2010, 2012a, 2012b).

O marxismo e a psicodinâmica do trabalho se desenvolveram em momentos históricos diferenciados e por sujeitos diferentemente implicados no seu contexto social e político. A extensa obra de Marx constituiu o esforço de empreender uma crítica à economia política liberal-burguesa e apreender o movimento real do capital enquanto uma relação social que se ampara na exploração do trabalho assalariado. Já o arcabouço teórico-clínico iniciado pelo francês Cristophe Dejours é uma tentativa de apresentar um novo olhar sobre o adoecimento relacionado ao trabalhar e as potencialidades do trabalho enquanto atividade deôntica.

$\mathrm{O}$ que há de convergente e divergente entre estas duas abordagens tão distantes no espaço, no tempo e na epistemologia? Quais as conexões possíveis entre os pensamentos de Marx e de Dejours? Quais as fronteiras epistemológicas e a possível interlocução entre essas duas concepções que têm na centralidade do trabalho seu fundamento? Esses são os questionamentos que movem este ensaio. A partir da explanação dos sentidos do trabalho para Marx, e da reconstituição da categoria trabalho no itinerário que levou Dejours da psicopatologia do trabalho à teoria do trabalho vivo - almejamos esboçar uma possível aproximação que forneça às nossas práticas clínicas um horizonte eminentemente político.

Sem a pretensão de dar cabo aos questionamentos levantados, as páginas que se seguem são um convite ao debate de ideias que não caminhe nem para $o$ ecletismo e tampouco para a ortodoxia.

\section{Fundamentos da teoria social marxiana}

Karl Marx dedicou grande parte de sua vida e obra à tentativa de apreender o movimento real do capital. Sua crítica dirige-se, fundamentalmente, ao modo de produção capitalista - ancorado na economia política liberal-burguesa - que enriquece um pequeno grupo social e condena a grande massa de trabalhadores à miséria e à pobreza (Netto, 2011). Para chegar à compreensão do cerne, da estrutura e da dinâmica do capital, e da forma de sociabilidade dele decorrente, Marx foi conduzido, inevitavelmente, à temática do trabalho. 
O trabalho, na obra marxiana, aparece em diversas dimensões, das quais destacamos: como força de trabalho, transformado em mercadoria pelo capital que, como tal, pode ser vendida e comprada; como trabalho abstrato, gerador de valores de troca, fundante do processo de valorização do capital e fonte da extração da mais-valor; como trabalho estranhado, fruto da degeneração produzida pela forma como se organiza na sociedade burguesa; e, finalmente, como trabalho concreto, produtor de valores de uso por meio do intercâmbio do homem com a Natureza, isto é, o trabalho como fundamento ontológico e condição indispensável à produção e reprodução da vida humana (Tumolo, 2005). É, nesse sentido, que podemos afirmar que $o$ movimento teórico e analítico realizado por Marx foi uma "inversão". Ele parte da compreensão do trabalho no capitalismo, do seu estágio de degeneração em "que o trabalhador baixa à condição de mercadoria e à mais miserável mercadoria [...]" (Marx, 1844/2010, p. 79) para a posteriori, buscar no trabalho concreto os fundamentos para a constituição do ser humano genérico e social.

No sentido genérico, na acepção marxiana, o trabalho consiste em:

[...] um processo entre $\mathrm{o}$ homem e a Natureza, um processo em que o homem, por sua própria ação, media, regula e controla seu metabolismo com a Natureza [...] Ele põe em movimento as forças naturais pertencentes à sua corporalidade, braços e pernas, cabeça e mão, a fim de apropriar-se da matéria natural numa forma útil para sua própria vida. Ao atuar, por meio desse movimento, sobre a Natureza externa a ele e ao modificá-la, ele modifica, ao mesmo tempo, sua própria natureza (Marx, 1867/2013a, pp. 31-32).

Trabalhar, no sentido concreto, é agir sobre a Natureza. É intervir na realidade material transformando-a a fim de atingir determinados objetivos, a fim de satisfazer às necessidades humanas. $\mathrm{O}$ trabalho, como reitera Marx, é uma atividade que pertence "exclusivamente ao homem" (Marx, 1867/2013a, p. 32). É o trabalho que diferencia o ser humano dos demais animais. Diferentemente das formas instintivas de trabalho, no processo de trabalho humano alcança-se um resultado que desde antes já existia na imaginação do trabalhador. $\mathrm{O}$ homem não promove apenas uma transformação na forma da matéria natural, mas adéqua ao seu objetivo, subordina à sua vontade, subjugando as forças da Natureza ao seu próprio domínio (Marx, 1867/2013a).

Desta forma, se pode afirmar que há uma relação intrínseca entre a existência humana e o trabalho. O trabalho, e todo desenvolvimento material dele imanente, só existem face à ação especificamente humana sobre a Natureza. Por sua vez, o homem só existe em razão de sua atividade produtiva, seu trabalho. O trabalho é "uma condição da existência do homem, independentemente de todas as formas de sociedade, eterna necessidade natural de mediação do metabolismo entre o homem e a Natureza e, portanto, da vida humana" (Marx, 1867/2004, pp. 64-65).

Ocorre que esse trabalho no sentido genérico, o trabalho concreto descrito por Marx, tem a sua existência limitada pelo modo de produção que, em tese, teria propiciado o maior desenvolvimento das forças produtivas desde os primórdios da humanidade. $\mathrm{O}$ capitalismo transforma $\mathrm{o}$ "processo de trabalho" (criador de valor de uso) em "processo de valorização" (criador de mais-valor).

Como explicita Tumolo:

$\begin{array}{lll}\text { Num } & \text { primeiro } & \text { exercício } \\ \text { analítico } & \text { percebe-se } & \text { que } o\end{array}$


trabalho concreto (valor de uso) está subsumido pelo trabalho abstrato (valor), em razão de que o capitalismo é uma sociedade essencialmente mercantil, cujo objetivo não é a produção de valores de uso para a satisfação das necessidades humanas, do estômago à fantasia. Mais do que isto, trata-se de uma relação na qual a afirmação do trabalho abstrato é a negação do trabalho concreto e viceversa. $\mathrm{O}$ desenvolvimento da força produtiva do trabalho, que é uma tendência inelutável do capital, agudiza tal contradição (Tumolo, 2005, pp. 242-243).

O trabalho em sua existência real o trabalho que se reproduz no modo de produção capitalista - é o trabalho assalariado, fetichizado e alienado. O modo de produção capitalista transforma o trabalhador em mercadoria cuja finalidade é produzir outras mercadorias e valorizar o capital. O trabalho, por sua vez, degenerase ao nível de uma atividade estranha que provoca a verdadeira desrealização do ser social e o estranhamento dos sujeitos que trabalham (Antunes, 2013).

Nos "Manuscritos econômicofilosóficos", Marx nos apresenta uma exegese sobre o lugar ocupado pelo trabalho na sociabilidade humana e a sua degeneração quando subordinado à lógica capitalista da propriedade privada dos meios-de-produção. Para o autor, "[...] o trabalho, a atividade vital, a vida produtiva mesma aparece ao homem apenas como um meio para a satisfação de uma carência, a necessidade de manutenção da existência física" (Marx, 1844/2010, p.84). Em suma, o trabalho estranhado subverte a relação a tal ponto: que a atividade vital do homem torna-se, apenas, um meio para a sua subsistência; que, quanto mais aumenta sua capacidade produtiva, mais miserável torna-se o trabalhador; que sua força de trabalho torna-se uma mercadoria tão menos valorosa quanto maior for a disponibilidade de trabalhadores vendendo sua força de trabalho; que, não apenas o produto do trabalho torna-se propriedade de outrem, como o próprio trabalho é aprisionado à propriedade do capitalista (Marx, 1844/2010).

$\mathrm{Na}$ sociedade das mercadorias, aos que vivem da venda de sua força de trabalho, resta apenas o cotidiano penoso e laborioso da produção. Como se não bastasse o aprisionamento do seu trabalhado à propriedade de outro e a expropriação do excedente daquilo que produz, o produto do seu trabalho emerge como um objeto estranho, como um objeto que se torna independente do seu produtor. A categoria alienação é uma síntese do que é o trabalho abstrato no capitalismo, e onde se expressam as relações conflituosas e de estranhamento do trabalhador: com o produto do seu trabalho, com o processo de produção, com os outros trabalhadores e consigo mesmo enquanto trabalhador (Marx, 1844/2010; Mészáros, 2016; Resende, 2009).

$\mathrm{Na}$ perspectiva do trabalho estranhado no modo de produção capitalista o que se verifica são os seguintes tipos de relação: 1) "A relação do trabalhador com o produto do seu trabalho como objeto estranho e poderoso sobre ele"; 2) "A relação do trabalhador com o ato de produção no interior do trabalho. Esta relação é a relação do trabalhador com a sua própria atividade como uma [atividade] estranha não pertencente a ele [...]"; 3) A relação em que "estranha do homem o seu próprio corpo, assim como a natureza fora dele, tal como a sua essência espiritual, a sua essência humana"; 4) E, finalmente, como consequência das relações de estranhamento anteriores "o estranhamento do homem pelo [próprio] homem", que é produto da "relação na qual ele mesmo se encontra como trabalhador" (Marx, 1844/2010, pp. 83-84). 
No capitalismo, o processo de trabalho torna-se "o processo de consumo da força de trabalho pelo capitalista" (Marx, 1867/2013, p.41). A análise marxiana empreendida nos serve à compreensão de como o trabalho, de condição básica e fundante de toda a vida humana, de substrato da sociabilidade, se estrutura no capitalismo como atividade responsável pela desefetivação do trabalhador. "Trata-se, pois, de trabalho que serve diretamente ao capital como instrumento de sua autovalorização, como meio para a produção de mais-valor". (Marx, 1867/2013, p. 126). De atividade simples, orientada à produção de valores de uso, torna-se o trabalho mero produtor de mercadorias e, o próprio trabalhador, uma mercadoria.

Não obstante, o trabalho ao ser apreendido também como práxis do ser social, como atividade histórica e dotada de um sentido político e que, como tal, se desenvolve imbricado nas contradições dos processos de alienação e estranhamento, engendra outras formas de sociabilidade que fomentam um horizonte de superação da sua forma mercantil e subsumida pelo modo de produção capitalista.

\section{Fundamentos da clínica psicodinâmica do trabalho}

Como já enunciado, a clínica psicodinâmica do trabalho surgiu a partir da prática profissional e da imersão - em diversos contextos de trabalho - do pesquisador francês Christophe Dejours. Como psiquiatra e médico do trabalho, o autor realizou inúmeros estudos $\mathrm{e}$ intervenções junto às mais diversas categorias profissionais na França, oportunidade que the rendeu o desenvolvimento de um novo corpus teórico-clínico acerca da relação entre saúde mental, subjetividade e trabalho.

Oriundo da Psicopatologia do Trabalho, Dejours propõe uma nova abordagem capaz de apreender não somente a doença, mas também a normalidade. Uma questão fundamental da psicodinâmica do trabalho é a seguinte: por que, submetidos às mesmas condições de trabalho e à mesma organização do trabalho, alguns trabalhadores adoecem e outros não? A partir desse questionamento, Dejours irá desenvolver os principais conceitos e categorias que irão dar sustentação à sua clínica do trabalho: a normalidade; a organização do trabalho; a mediação entre prazer e sofrimento no trabalho; os destinos do sofrimento no trabalho; as defesas individuais e coletivas; as relações de solidariedade e cooperação; a inteligência astuciosa; a dinâmica do reconhecimento; etc. (Dejours, 1990/2009; 1993/2004).

Ao explicitarem sua ruptura com o "modelo causalista" da Psicopatologia do Trabalho, Dejours e Abdoucheli afirmam:

Por uma derivação, esboçou-se, pouco a pouco, outro modelo teórico que tentava dar conta dos dados empíricos, buscando sobretudo tematizar o sofrimento no trabalho e as defesas contra o sofrimento. Um modelo no qual os trabalhadores permanecem, sejam quais forem as circunstâncias, sujeitos de seu trabalho, pensam sobre sua situação e organizam seu comportamento e seu discurso, com uma coerência fundada na compreensão que se supõe que eles tenham da condição que seu estado traz ao trabalho (Dejours \& Abdoucheli, 1990/2009, p.121).

$\mathrm{Na}$ compreensão de Pascale Molinier (2013, pp. 66-69), o direcionamento da psicodinâmica do trabalho para as temáticas da normalidade e do sofrimento, em detrimento da doença, representa uma verdadeira "reviravolta epistemológica". Mais do que isso, 
abandonar o "conforto" dos modelos causalistas e ampliar os horizontes de análises irá obrigar a psicodinâmica do trabalho a se reposicionar em outro campo disciplinar. A teoria dejouriana não mais caberia na medicina ou na psiquiatria. À revelia dos esforços de Le Guillant para integrar a psiquiatria às ciências sociais, quem conseguiu cruzar a fronteira, segundo a autora, teria sido a clínica psicodinâmica do trabalho (Molinier, 2012, pp. 66-69).

Vejamos, a nova teoria abandona a suposta passividade do sujeito frente à organização do trabalho - agora não mais apreendida como um "dado preexistente" ou um "bloco rígido". Enfoca-se a normalidade, não como sinônimo de saúde, e sim como um equilíbrio precário e instável entre o sofrimento e as defesas contra o sofrimento. Sabe-se, também, que os trabalhadores dependem de seus pares, e que a própria organização do trabalho se constrói nas relações intersubjetivas entre homens e mulheres nas situações ordinárias de trabalho - não sem a influência, obviamente, da hierarquia, da evolução da técnica e das teorias de gestão (Dejours, 1993/2004a, pp. 50-58).

Como o próprio Dejours nos adverte, "a psicodinâmica do trabalho é antes de tudo umas práxis" (Dejours, 1993/2004a, p. 56). Tendo como fonte primária as investigações clínicas do próprio autor, vez ou outra, a psicodinâmica se esquivou de algumas questões teóricas elementares. A própria definição do que é trabalho - e mais recentemente, a invocação da centralidade do trabalho - são fundamentos que, no nosso entendimento, ainda estão inconclusas ou aparecem de forma difusa, e que apontam a necessidade de uma reconstituição filosófica, epistemológica e ontológica das bases teóricas da clínica dejouriana.

Tomando por referência diversas matrizes, desde a ergonomia até a psicanálise, passando pela sociologia compreensiva, pela teoria da ação comunicacional de Habermas, pela filosofia de Hannah Arendt, pela fenomenologia do corpo de Michel Henry e Merleau-Ponty e, mais recentemente, dialogando com a teoria crítica da sociedade, a psicodinâmica carece de uma reconstituição teórica e epistemológica, sobretudo com relação à sua categoria fundante: o trabalho (Dejours, 2010, 2013). Desde as primeiras formulações de Dejours, percebe-se suficiente clareza e convicção acerca dos impactos do trabalho sobre o aparelho psíquico, clareza esta que pode vir a ser melhor desenvolvida em relação à delimitação da própria categoria trabalho.

Talvez uma das primeiras definições do que é o trabalho, na clínica psicodinâmica, seja aquela inspirada pela sua matriz ergonômica. Afirma Dejours (1993/2004a, p.65) que o trabalho "é a atividade manifestada por homens e mulheres para realizar o que ainda não está prescrito pela organização do trabalho". Complementa ainda o autor: trabalhar é "preencher o espaço entre o prescrito e o efetivo" (Dejours, 2008, p. 39). Com o desenvolvimento das tecnologias, das teorias e técnicas de gestão, a organização do trabalho se constituiu como uma totalidade tão complexa, tão dotada de normas, regras e prescrições, que se torna impossível executar a tarefa com eficiência frente às exigências e limitações impostas pela própria organização do trabalho. Criou-se um verdadeiro hiato, um intervalo irredutível entre $\mathrm{o}$ trabalho prescrito (tarefa) e o trabalho real (atividade), discrepância esta que também é fonte inesgotável de sofrimento para o sujeito que trabalha (Dejours, 1995, 2005, 2008, 2012b).

Neste sentido, trabalhar é tudo que o sujeito coloca de si (do seu corpo, da sua inteligência, do seu engajamento, da sua subjetividade) para preencher o hiato entre o prescrito e o efetivo. Nas palavras de Dejours (2004, p.38): 
[...] o trabalho é aquilo que implica, do ponto de vista humano, o fato de trabalhar: gestos, o saber-fazer, um engajamento do corpo, a mobilização da inteligência, a capacidade de refletir, de interpretar e de reagir às situações; é o poder de sentir, de pensar e de inventar, etc. Em outros termos, para o clínico, o trabalho não é em primeira instância a relação salarial ou o emprego; é o «trabalhar», isto é, um certo modo de engajamento da personalidade para responder a uma tarefa delimitada por pressões (materiais e sociais).

Outra compreensão corrente na psicodinâmica do trabalho - e que remete à sua segunda matriz teórica significativa, a psicanálise freudiana - é análise do trabalho do ponto de vista da sua importância na economia psíquica. Para Dejours, o trabalho é uma ferramenta importante para a canalização das energias pulsionais (interiores), bem como para a descarga das excitações provenientes dos estímulos exteriores. Desta forma, o trabalho pode se tornar fatigante ou equilibrante, na medida em que é capaz de dar vazão ou não à carga psíquica do sujeito. Afirma o autor que "em se tratando de carga psíquica, o perigo principal é o do subemprego de aptidões psíquicas, fantasmáticas ou psicomotoras, o que ocasiona uma retenção da energia pulsional, o que constitui precisamente a carga psíquica de trabalho" (Dejours, 1980/2009, p.24).

$\mathrm{Na}$ mesma esteira da economia psíquica, e também seguindo os preceitos da metapsicologia, Dejours aponta o trabalho como uma importante atividade sublimatória. $\mathrm{Na}$ psicanálise freudiana, a sublimação consiste na renúncia à satisfação sexual e no direcionamento da energia psíquica para objetos não sexualizados e de valor social movimento psíquico estritamente necessário ao processo civilizatório, ao estabelecimento da cultura e à normalidade do indivíduo (Amaral, Mendes, Chatelard \& Carvalho, 2017).

Para Dejours, a sublimação também consiste em um trabalho do psiquismo o qual se dá, especialmente, por meio do trabalho de produção. A sublimação, na clínica psicodinâmica do trabalho, se dá em três dimensões: no trabalho psíquico sobre si mesmo, por meio da convocação da inteligência e do corpo; no trabalho enquanto uma relação mediatizada pela dinâmica do reconhecimento pelo outro; e no trabalho enquanto atividade deôntica capaz contribuir para o estabelecimento da cultura e para as relações sociais na polis. Como se deve supor, tampouco a organização cientifica do trabalho (taylorismo), como as novas formas de organização reestruturadas fornecem as condições para que o sujeito realize o recurso subjetivo à sublimação por meio da sua atividade laboral, de modo que tal impedimento só pode contribuir para o caminho do sofrimento patológico (Amaral et al., 2017; Dejours, 1982/1993; 2013)

Como já indicado, trabalhar não é apenas produzir, é trabalhar sobre si mesmo, sobre a própria subjetividade. Aqui temos uma terceira e importante compreensão sobre o papel do trabalho para a clínica psicodinâmica: a sua relação com a constituição subjetiva e o desenvolvimento da identidade. Nas palavras de Dejours (2004, p.30), “o trabalho não é redutível a uma atividade de produção no mundo objetivo [...] $\mathrm{O}$ trabalho constitui, para a subjetividade, uma provação que a transforma". Mais do que a simples transformação da matéria, mais do que a modificação da natureza, o trabalho se apresenta como uma ocasião em que a subjetividade é colocada à prova, podendo ou não realizar-se, podendo sair acrescentada, enaltecida ou, ao contrário, diminuída, mortificada. (Dejours, 2004; 2012). 
Para Dejours (2010), o processo de ampliação da subjetividade por meio do trabalho se dá em dois níveis:

a) No nível individual: no trabalho ordinário de produção (poiesis) o sujeito experimenta o "real do trabalho" o qual, via de regra, the aparece na forma de fracasso. Nos esforços de enfrentar $o$ desconhecido, de vencer as resistências do real, de superar as prescrições da tarefa, o sujeito vê-se obrigado a desenvolver soluções criativas, empregar sua inteligência, suas percepções, suas habilidades corporais e a sua sensibilidade. Experimentar a resistência do real do trabalho é também uma maneira de experimentar o mundo e dele se apropriar, tanto no sentido físico como metafórico. Através da experimentação do real do trabalho e dos esforços objetivos para superar suas resistências, as capacidades do corpo e da subjetividade são expandidas, de modo que se pode afirmar que "o trabalho sobre o mundo também oferece um trabalho criativo da subjetividade sobre si mesmo" (Dejours, 2010, p.172, tradução livre).

b) No nível social: por meio de relações específicas de reconhecimento que extrapolam o status social ou a importância do trabalho. Uma forma de reconhecimento baseada no saber-fazer do trabalhador, na qualidade da relação que ele mantem com o real do trabalho. É o reconhecimento de sua inteligência astuciosa (metis), de sua contribuição ativa frente ao real do trabalho, reconhecimento este que só pode ser dado pelos seus pares que também conhecem e vivenciam aquela atividade.

Esses dois processos interdependentes, a recompensa simbólica proporcionada mediante o reconhecimento pelos pares e o engajamento do sujeito (do corpo ao psiquismo) para enfrentar o real do trabalho - que se apresenta como representação do real mundo, do real da vida - constituem fonte importante de aprimoramento da subjetividade e desenvolvimento da identidade (Dejours, 2010, pp. 170 -172).

Supõe-se, até o presente momento, qual é o papel do trabalho na constituição da subjetividade, isto é, "o que a subjetividade deve ao trabalho" (Dejours, 2004, p. 30). Adiante, no decorrer do seu desenvolvimento teórico, Dejours retoma esse questionamento de forma inversa: o que deve o trabalho à subjetividade? É aqui que se torna importante e necessário $\mathrm{o}$ conceito de trabalho psíquico ou trabalho do psiquismo. Também com referência na psicanálise, Dejours irá resgatar o conceito freudiano de Arbeit (trabalho), o qual na metapsicologia pode figurar como: trabalho do sonho, esforço de trabalho (Erinnerungsarbeit), trabalho de interpretação (Therapeutischearbeit), trabalho do luto (Trauerarbeit), trabalho do recalcamento (Verdrägunsgarbeit), trabalho de condensação (Verdichtungsarbeit), trabalho da cultura (Kulturarbeit), perlaboração (Durcharbeit), dentre outras significações (Dejours, 2012, p.193).

Para Dejours, o trabalho de produção (poiesis) e o trabalho do psiquismo (Arbeit) são complementares, se interpõem, ou melhor, um é prolongamento do outro. Ao passo que a apropriação da experiência do trabalho ordinário (poiesis) garante a ampliação da subjetividade, é por meio do trabalho do psiquismo (Arbeit) que o sujeito garantirá a aquisição de uma nova habilidade, de novas competências ou de um saber-fazer singular a ser empregado no seu trabalho produtivo (Dejours, 2012a).

Explicita o autor que:

Ademais, ocorre mesmo que, devido ao insucesso dos resultados, eu não consiga dormir. Tenho insônias, sonho, são pesadelos sobre meu trabalho. Pois bem, isso também é parte integrante do trabalho! É impossível 
demonstrar que é necessário sonhar com o seu trabalho para tornar-se hábil, adquirir destreza. Incorporar a matéria do seu trabalho, isso implica ser por ele tomado até mesmo em sonho. E é graças a todo este trabalho interno que se obtém esta familiaridade com a tarefa. O trabalho do sonho é a parte interna do remanejamento da personalidade que impõem os constrangimentos e o real do trabalho àquele que apresenta esta qualidade: a obstinação em prosseguir ante o insucesso. Encontrar soluções, inventar novos caminhos, isso passa por uma transformação de si, profunda. O trabalho não cessa no ateliê, na fábrica ou no hospital. Ele coloniza toda a subjetividade"

(Dejours, 2012a, pp. 50-51).

Por intermédio do exposto é que caminhamos, em conjunto com o desenvolvimento teórico de Dejours desde suas origens na psicopatologia até a clínica psicodinâmica do trabalho - para o que o autor chama de "trabalho vivo". E afirmamos, sem ressalva, que a psicodinâmica do trabalho pode também ser chamada de Teoria do Trabalho Vivo. Pois o trabalho; não é mera atividade de produção, não é mera relação salarial, não é simplesmente condição de sobrevivência ou fonte de adoecimento. O trabalho é toda essa atividade complexa que envolve do corpo ao psiquismo, do saber-fazer à subjetividade, da experiência do fracasso ao desenvolvimento da identidade. Para uma Teoria do Trabalho Vivo, o trabalho é: gerador intrínseco de sofrimento, mas também de prazer e reconhecimento; atividade sublimatória e ferramenta indispensável à economia do psiquismo; atividade subjetivante e mobilizador de toda a subjetividade; é trabalho de produção, mas é também trabalho psíquico de elaboração; e ainda, como veremos adiante, é o trabalho central à organização da vida em sociedade (Dejours, 2012).

\section{Psicodinâmica do trabalho e marxismo: aproximações necessárias}

Que o trabalho era central à constituição da subjetividade, já se afirmava desde as primeiras formulações da clínica psicodinâmica do trabalho. No entanto, seu papel no estabelecimento das relações sociais e políticas no âmbito mais geral é, digamos, uma "descoberta" recente. Desde "A banalização da injustiça social" (1998/2007) Dejours vem amadurecendo a sua compreensão sobre a centralidade do trabalho, a qual somente será consolidada com a publicação de "Trabalho Vivo" (2012). Para o autor, o trabalho é central: em relação à saúde do sujeito; no que tange às relações sociais de gênero; na produção do conhecimento sobre o mundo; e no seu papel estruturante da economia, da política e da vida na cidade. É esta última dimensão que nos interessa, particularmente, e a partir da qual almejamos propor uma aproximação crítica com a teoria social marxiana (Dejours, 1998/2007, 2012a, 2012b, 2017);

Em "Trabalho vivo: Trabalho e emancipação", Dejours (2012b, p. 175) afirma que a centralidade epistemológica do trabalho vem caminhado ao encontro da centralidade política do trabalho. Segundo o autor, a cada dia torna-se mais notável que a divisão social do trabalho $\mathrm{e}$ a fragmentação imposta pela nova racionalidade produtiva não ficam restritas aos ambientes laborais, mas transcendem para a vida do sujeito e para a organização da sociedade. Neste sentido, torna-se necessário pensar o trabalho não apenas como o trabalho alienado, determinante do sofrimento e da despersonalização do trabalhador, mas também como atividade potencialmente orientadora de uma ação política coletiva e de subversão da 
dominação social (Dejours, 2012b, p.185189).

Nesse volume, em particular, Dejours empenha-se na (re)construção de "um conceito crítico de trabalho" o que, segundo o autor, escapa às formulações teóricas desde as contribuições de Marx. Para tanto, faz-se necessário desvelar as descobertas da clínica psicodinâmica quanto aos "recursos substanciais que encerra $o$ trabalho em relação ao viver junto, à construção das solidariedades e à formação da vontade coletiva de agir (pelo viés da cooperação e da deontologia do fazer" (Dejours, 2012b, p.185).

Não há trabalho sem cooperação, afirma Dejours. E isso nos conduz à atividade deôntica como condição fundante para que o trabalho humano possa assumir seu potencial para a emancipação. Por atividade deôntica, compreende-se a atividade de produzir regras de ofício para que o trabalho funcione. Mas esse simples ato só pode ser efetivado pelos trabalhadores em conjunto - no tête-à-tête, no ombro a ombro - e por meio dos espaços coletivos de deliberação, de modo que essas regras - a princípio técnicas assumam uma dimensão social intrínseca. Trabalhar não é apenas produzir, destaca o autor, é também aprender a viver juntos. (Dejours, 2012b).

$\mathrm{E}$, ao afrentarem em conjunto o real do trabalho e uma organização do trabalho que limita a cooperação e os espaços coletivos de deliberação, a atividade deôntica torna-se, eminentemente, política. Assim, o trabalho pode ser central à "regeneração" ou à "deserção" do político. Vejamos:

"Afirmar que o trabalho em certas formas de organização do trabalho constitui um poder regenerador do político é também dizer que outras formas de organização do trabalho constituem de fato métodos de governança capazes de prejudicar também na esfera do político [...] Em razão de seu impacto sobre a mobilização e a desmobilização da vontade de agir dos trabalhadores, a organização do trabalho pertence, quer queira quer não, à ordem do político, para o melhor e o pior!" (Dejours, 2012b, p.192).

Se a organização do trabalho tem uma dimensão política intrínseca que pode provocar nos trabalhadores a afeição ou desafeição pela política, depreende-se que o trabalhar "é todo ele político" (Dejours, 2012b, p. 170). Se, por um lado, a organização da sociedade fornece as bases morais e os valores sociais que se reproduzem no trabalho e nas relações entre os trabalhadores, é possível também pensar o caminho inverso: em que medida a organização do trabalho e o trabalho enquanto atividade deôntica contribuem para a produção e reprodução das relações sociais e políticas no âmbito geral da sociedade? Em que medida o trabalho pode contribuir efetivamente para resgatar os laços de solidariedade e cooperação e construir um caminho para a emancipação? Como o trabalho de produção em nível individual (poiesis) pode converter-se em atividade prático-crítica no nível coletivo (práxis)?

A aproximação mais sistemática e direta de Dejours com a teoria social marxiana se deu recentemente ${ }^{2}$, por meio do debate com os teóricos da Escola de Frankfurt, em particular com Axel Honneth. Tal como Honneth, Dejours está interessado na construção de um conceito

\footnotetext{
${ }^{2}$ Sabe-se que desde as suas primeiras publicações é possível perceber referências, diretas ou indiretas, ao marxismo, como por exemplo quando o autor lança mão da categoria alienação, já em A loucura do Trabalho, de 1980. No entanto, o diálogo direto com Marx é recente, e irá figurar a partir da publicação de The Centrality of work (Dejours \& Deranty, 2010) e, notadamente, no segundo volume de Trabalho Vivo: trabalho e emancipação (Dejours, 2012b).
} 
crítico de trabalho. Ambos assinalam uma lacuna no pensamento marxiano, o fato de que Marx nunca foi capaz de explicar a tese segundo qual a emancipação dos trabalhadores se daria a partir das relações inerentes ao próprio trabalho alienado no modo de produção capitalista. Se Dejours questiona o preceito marxiano de que todo o trabalho no capitalismo é alienado, ele toma para a sua teoria do trabalho vivo o viés do trabalho como caminho para a emancipação (Dejours, 2012b; Honneth, 2007).

Dissidindo de Habermas - um dos seus principais interlocutores -, e do próprio Marx, em certa medida, Dejours afirma ser o momento necessário de deixar de atribuir ao trabalho os "predicados típicos" da servidão e da dominação. É preciso acordar ao "trabalho concreto" o lugar (Dejours, 2012b, p. 174) que lhe cabe no direcionamento para a emancipação. Afirma o autor que:

A referência à emancipação não tem por objetivo apenas o processo pelo qual seria possível escapar da alienação mental. Não diz apenas respeito ao domínio da saúde mental. Pelo termo emancipação designa-se também o processo que permitiria aos nossos contemporâneos um retorno à arena do político, que têm tendência de desertar sob efeito de um sentimento de profunda impotência diante da força colossal da transformação implantada pelas empresas multinacionais (Dejours, 2012, p.209).

Podemos afirmar que a "descoberta" da organização do trabalho como um importante "gerador do político" trouxe um novo direcionamento à clínica psicodinâmica do trabalho. É notável que a emancipação a qual se refere Dejours nem de longe se aproxima do que propõe Marx - de uma superação das bases materiais que sustentam o modo de produção capitalista. No entanto, podemos considerar "Trabalho vivo: trabalho e emancipação" como um marco teóricopolítico na obra dejouriana: não basta à clínica do trabalho apenas intervir na organização do trabalho, é preciso acumular forças e ampliar os horizontes para alcançar a raiz do problema: construir uma nova teoria do trabalho e uma política do trabalho integral (Dejours, 2012b, p. 204).

Pensar uma política do trabalho integral significa colocar em debate as relações significativas entre "o trabalho e a polis, entre o trabalho e a violência ou a civilidade, entre o trabalho e a escola, entre o trabalho e a cultura, entre o trabalho e a democracia". É também problematizar a influência que as políticas neoliberais, as novas teorias de gestão e as práticas de gerenciamento têm na constituição de relações sociais e de trabalho artificiais, fragmentárias e adoecedoras. (Dejours, 2007; Dejours, 2012b, p.204). E isto - tal como uma nova teoria do trabalho somente se tornará possível, no nosso entendimento, a partir de uma reconstituição crítico-ontológico da categoria trabalho por meio de uma apreensão radical - isto é, que vá à raiz da questão - de suas mediações no seio da estrutura e da dinâmica da sociedade capitalista. E é aqui que as formulações da teoria social marxiana têm muito a contribuir para a clínica psicodinâmica do trabalho.

\section{Considerações finais}

Neste ensaio, a partir da explanação dos sentidos do trabalho em Marx, e da reconstituição do itinerário teórico que levou Dejours da psicopatologia do trabalho à teoria do trabalho vivo, indicamos um caminho possível para uma aproximação entre estas duas concepções - 
ainda que uma análise mais apurada das bases epistemológicas de cada um dos autores torne a tarefa bastante complexa.

Como nos chama a atenção o próprio Dejours, faz-se necessário superar a superficialidade conceitual e empírica com a qual a categoria trabalho foi e vem sendo tratada pelas ciências do trabalho para, de fato, penetrar na materialidade do trabalhar e nos processos subjetivos $\mathrm{e}$ coletivos dele decorrentes - seja do trabalho individual de produção ou da deontologia do fazer juntos (Dejours, 2012b). Não ignorando as limitações políticas da clínica psicodinâmica do trabalho e, tampouco, a insuficiência ou quase inexistência de uma teoria da subjetividade em Marx, o que estamos propondo aqui é uma aproximação crítica entre os dois campos de pensamento que seja capaz de - na medida em que rompe as barreiras epistemológicas colocadas pela substância das categorias inerentes à cada abordagem - nos forneça um horizonte crítico-político para as nossas práticas clínicas.

Esse percurso passa pela reconstituição crítica da categoria trabalho e pela emergência de uma política do trabalho alçados por um olhar ontológico sobre o papel do trabalho concreto e sua situação abstrata sob a égide do modo capitalista de produção, das políticas neoliberais e da gestão toyotizada. Resgatar os sentidos potenciais do trabalho em Marx e Dejours - não somente na constituição do ser humano genérico, mas na edificação de relações de solidariedade e cooperação - e defender uma política do trabalho, é contrapor-se à despolitização e ao esvaziamento da categoria trabalho que tem dominado a Psicologia do Trabalho e das Organizações (POT) e as demais ciências do Trabalho na atualidade.

\section{Referências}

Amaral, G.A., Mendes, A.M., Chatelard, D.S., \& Carvalho, I. (2017). O lugar do conceito de sublimação na psicodinâmica do trabalho. Revista Polis e Psique, 7(3), 200-223. Recuperado em 5 de janeiro, 2018, de http://seer.ufrgs.br/index.php/PolisePsi que/article/view/66740/pdf.

Antunes, R. (2013). Apresentação. In: Antunes, R. (Org.). A dialética do trabalho: escritos de Marx e Engels. São Paulo: Expressão Popular.

Camus, A. (2010). O mito de Sísifo: ensaio sobre o absurdo. Rio de Janeiro: Record.

Dejours, C. (1980/1995). A loucura no trabalho: estudo de psicopatologia do trabalho. 5 ed. ampliada. São Paulo: Cortez-Oboré.

Dejours, C. (1993/2004). Addendum: da psicopatologia à psicodinâmica do trabalho. In: Lancman, S.; Sznelwar, L. (Orgs.). Cristophe Dejours: da psicopatologia à psicodinâmica do trabalho, pp. 47-103. Brasillia: Paralelo 15.

Dejours, C. (2004). Subjetividade, trabalho e ação. Revista Produção. 14(3), p. 27-34, set./dez. Recuperado em 12 de janeiro, 2018 , de http:/www.scielo.br/pdf/prod/v14n3/v 14n3a03.pdf

Dejours, C. (2005). O fator humano. 5 ed. Rio de Janeiro: Editora FGV.

Dejours, C. (1998/2007). A banalização da injustiça social. Rio de Janeiro: Editora FGV.

Dejours, C. (2008). Avaliação do trabalho submetido à prova do real: crítica aos fundamentos da avaliação. Caderno de $T T O$, n. 2. São Paulo: Blucher. 
Dejours, C. (1980/2009). A carga psíquica do trabalho. In: Dejours, C., Abdoucheli, E., \& Jayet, C. (Orgs.). Psicodinâmica do trabalho: contribuições da escola dejouriana à análise da relação prazer, sofrimento $e$ trabalho, pp. 21-32. São Paulo: Atlas.

Dejours, C. (1990/2009). Itinerário teórico em psicopatologia do Trabalho. In: Dejours, C., Abdoucheli, E., \& Jayet, C. (Orgs.). Psicodinâmica do trabalho: contribuições da escola dejouriana à análise da relação prazer, sofrimento e trabalho, pp. 119145. São Paulo: Atlas.

Dejours, C., \& Deranty, J.P. (2010). The centrality of work. Critical Horizons. 11(2), 167-180. Recuperado em 10 de janeiro, 2018, de: https $/ /$ student.cc.uoc.gr/uploadFiles/1 $81-$ \%CE\%92\%CE\%99\%CE\%9F\%CE\% 9 A275/DejoursWork.pdf

Dejours, C. (2012a). Trabalho vivo: trabalho e sexualidade. Brasilia: Paralelo 15.

Dejours, C. (2012b). Trabalho vivo: trabalho e emancipação. Brasîlia: Paralelo 15.

Dejours, C. (2013). A sublimação, entre sofrimento e prazer no trabalho. Revista Portuguesa de Psicanálise. 33(2), 9-28. Recuperado em 6 de janeiro, 2018, de http://docplayer.com.br/24920304-Asublimacao-entre-sofrimento-e-prazerno-trabalho-1.html

Dejours, C. (2017). Prefácio. In: Dejours, C. (Org.). Psicodinâmica do trabalho: casos clínicos. Porto Alegre: Dublinense.

Honneth, A. (2007). Travail et agir instrumental. À propôs des problèmes catégoriels d'une théorie critique critique de la sociéte. Travailler, n.18, pp. 17-57. Recuperado em 21 de janeiro, 2018, de: https://www.cairn.info/revuetravailler-2007-2-page-17.htm

Marx, K. (1844/2010). Manuscritos econômico-filosóficos. São Paulo: Boitempo editorial.

Marx, K. (1967/2004). O capital: crítica da economia política (Livro 1). Rio de Janeiro: Civilização brasileira.

Marx, K. (1867/2013a). Processo de trabalho e processo de valorização. In: ANTUNES, R. (org.) A dialética do trabalho: escritos de Marx e Engels (Vol. I, 2ed, p. 31-58). São Paulo: Expressão Popular.

Marx, K. (1867/2013b). Trabalho produtivo e trabalho improdutivo. In: ANTUNES, R. (org.) A dialética do trabalho: escritos de Marx e Engels (Vol. I, 2ed, p. 125-138). São Paulo: Expressão Popular.

Mészáros, I. (2016). A teoria da alienação em Marx. São Paulo: Boitempo editorial.

Molinier, P. O trabalho e a psique: uma introdução à psicodinâmica do trabalho. Brasîlia: Paralelo 15.

Netto, J. P. (2011). Introdução ao estudo do método em Marx. São Paulo: Expressão Popular.

Resende, A. C. (2009). Para a crítica da subjetividade reificada. Goiânia: Editora UFG.

Tumolo, P. S. (2005) O trabalho na forma social do capital e o trabalho como princípio educativo: uma articulação possível. Educação \& Sociedade, 26(90), 239-265. Recuperado em 3 de janeiro, 2018 , de 
http://www.scielo.br/pdf/es/v26n90/a1

1v2690.pdf

Data de Submissão: $05 / 02 / 2018$

Data de Aceite: $\quad$ 26/03/2018 